\title{
In-vitro Bioequivalence Study Between four Different Marketed Formulations of Gliclazide with Sustained Release Metformin Hydrochloride Tablet as an Anti- Diabetic Drug
}

\author{
Jyoti Chauhan ${ }^{1}(\mathbb{D})$, Pankaj Giri ${ }^{2 *(D)}$, Yamini Chandola ${ }^{3}$, Paranshu Tangari ${ }^{3}$ (D), Nidagurthi Guggilla \\ Raghavendra Rao ${ }^{4}$ (D) \\ 1 Department of Pharmaceutics, Guru Ram Das (PG) Institute of Management \& Technology, Dehradun, Uttarakhand \\ 2 Department of Pharmaceutics, Chitkara College of PHARMACY, Chitkara University Punjab \\ 3 Department of Pharmaceutics, Faculty of Pharmacy, Guru Ram Das (PG) Institute of Management \& Technology, \\ Dehradun, Uttarakhand \\ 5 Department of Pharmaceutics, Director of Pharmacy, Guru Ram Das (PG) Institute of Management \& Technology, \\ Dehradun, Uttarakhand \\ * Correspondence: raksatra90@gmail.com;
}

Scopus Author ID 57216966406

Received: 21.05.2020; Revised: 18.06.2020; Accepted: 20.06.2020; Published: 26.06.2020

\begin{abstract}
As per the granted biowaiver by the United States Food and Drug Administration, the invitro method is an alternative to find out bioequivalence. In the performed study, a finished product test was performed between the brand drug and the generic drugs to find out the consistency of generic drugs. In the recent era, generic medicine is encircled all over the market to reduce the cost of medicine so that the drug to be available to all the individual in minimum prices for that In-Vitro Bioequivalence is conducted for a different formulation of drugs for the assessment of different formulation of same drugs or alike active pharmaceutical ingredients. The main objective of this study is to find out the invitro bioequivalence, evaluate the parameters which impact on dissolution profile, and assemble the research work.
\end{abstract}

Keywords: Generic medicine; Dissolution; Bioequivalence; In-vitro; Biowaiver.

(C) 2020 by the authors. This article is an open-access article distributed under the terms and conditions of the Creative Commons Attribution (CC BY) license (https://creativecommons.org/licenses/by/4.0/).

\section{Introduction}

As per Birkett et al. bioequivalence is, the different dosage form of the same drug are bioequivalent if their rate and extent of availability after taking by the oral route are identical concerning the efficacy, safety, and blood plasma concentration, all four dosage form should be comparable in all parameters[1].

Bioequivalence was required by United States Food and Drug Administration (FDA), there are no significant change in the dosage form and/or active ingredients rate and extent after oral administration at similar dose under the identical condition, and same concentration is available at the site where the drug shows its action [2].

In-vitro bioequivalence is performed by maintaining the dissolution condition in the dissolution apparatus after setup of the dissolution apparatus sample is withdrawn, and the percentage of drug release can be determined by using high-performance liquid chromatography. Bioequivalence study can be performed by two means, i.e., by creating a 
similar environmental condition the same as inside the body and animal model testing. Bioequivalence study, however, the in vitro method is best in terms of cost reduction. The biowaiver granted by the US FDA, which means in-vivo bioequivalence studies not considered necessary for product approval. As an alternative to the in-vivo studies, a dissolution test method is a less expensive and less time consuming [4].

\subsection{Diabetes.}

Diabetes is a metabolism disorder of carbohydrates, fats, protein. It is a disease resulting from defective and/or lack of insulin characterized by hyperglycemia in which autoimmunity destructs the beta-cell of pancreases [23]. There are two types of diabetes, i.e., type -1 diabetes mellitus and type -2 diabetes mellitus. Insulin treatment is given in type -1 diabetes, whereas the therapeutic approach is given in type -2 diabetes. Vital organs of the body involved in the regulation of glucose level in valance the blood are skeletal muscle, pancreas, liver, kidney, adipose tissue, and intestine.[18] Diabetes can cause various complications like hinder wound healing phenomenon [5], cause kidney disease [6] Weaken the immunity system [4] In the diabetes blood glucose level are controlled by anti-diabetic drugs, maximum anti-diabetic drugs are taken by orally except insulin [3].

\subsection{Type 1 diabetes mellitus.}

Type 1 constitutes approx. 5-10\% of cases also called insulin-dependent diabetes, and it is most common in adults, children, and teenagers, although in the past, it is discovered that it can occur to anyone. [7]. In this diabetes, insulin is not secreted by the beta cell in the pancreas as a result of a disturbance in body immunity and hence beta-cell are destroyed by antibodies, consequence lack of insulin [8-11] insulin via injection and/or infusions by insulin pumps are necessary for type 1 patients [3].

\subsection{Type 2 diabetes mellitus.}

It constitutes around 85-95\% cases, and it is the most common also called non-insulindependent diabetes mellitus and mostly occurs in people having age 45 or more [12], and the younger generation was also caught with this type of diabetes. Insulin is secreted normally in the beta cell of the pancreas, but the insulin receptor present in the cell membrane is not able to take the uptake of insulin normally. Hence cell becomes resistant to insulin which results in a rise in the blood.

\subsection{Gestational diabetes.}

It occurs during the development phases of pregnancy. A common treatment is maintaining diet and doing exercises. However, some anti-diabetic drugs are given to maintain the blood glucose level. [13] Complication include overweightness, obesity [14].

\subsection{Function of insulin in the body.}

It maintains the blood glucose level by transferring the blood glucose to tissues of the body from carbohydrates [3]. 


\subsection{Anti-diabetic drug-mechanism of action.}

Metformin: It reduces hepatic blood glucose level and works by acting on AMPK dependent and AMPK-independent mechanisms are available to cure diabetes mellitus 2 [15]. The drug belongs to class III biopharmaceutical system of classification having high solubility and low permeability, and rate-limiting step is the membrane permeability, absorption kinetics be subjected to the biopharmaceutical and physiological factor instead of formulation factor.[4] Bioavailability of Metformin is 50-60\%, and its peak plasma concentration-time is nearly 2 hours, and elimination half-life is 4-6 hours. Structure of Metformin, as shown in Figure 1 below:

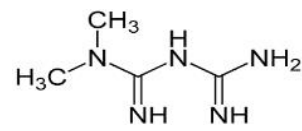

Figure 1. Chemical structure of Metformin.

Gliclazide: It is a second-generation sulphonylurea agent and used for the treatment of the type of diabetes occurrence of which does not depend on insulin release (type 2 diabetes) [16], it works by stimulating beta cell of the pancreas. As a result, the beta-cell release insulin, and due to their mechanism of action, it causes low blood glucose levels, so regular food uptake is necessary. It comes under the II class biopharmaceutical classification system. Its oral bioavailability is subject to drug dissolution and solubility in the GI tract (gastrointestinal tract), poorly water-soluble, and having a lower solubility of its solution in the acid medium [21]. Peak plasma concentration-time is nearly 3 hours, the elimination half-life is approximately 10-12 hours, and the bioavailability of the drug is $80 \%$ Structure of Gliclazide as shown in Figure 2 below:

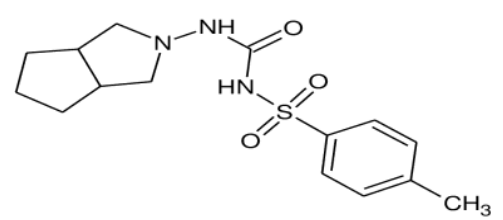

Figure 2. Chemical structure of the Gliclazide structure.

\section{Materials and Methods}

\subsection{Materials.}

Drugs: Four different formulations of same drug Gliclazide with sustained-release metformin hydrochloride tablets were used in the study the innovator sample used as a reference drug was gifted from a local supplier. The generic drugs are taken from the registered pharmacist at Haridwar, during the study the materials used are phosphate buffer $\mathrm{pH}$ 7.4, water, sodium hydroxide, Trifluoroacetic acid, Acetonitrile, Methanol, Nylon membrane, Orthophosphoric acid.

\subsection{Evaluation Parameters of the Tablets.}

2.2.1 Weight variation test.

20 tablets were weighed using digital analytical balance to find out the average weight [17], the individual tablet was weighed to check the weight variation and calculated by the following formula: 


$$
=\frac{\text { Minimum } / \text { Maximum weight }- \text { average weight } \times 100}{\text { Average weight }}
$$

\subsubsection{Hardness.}

10 tablets were selected, placed the tablets horizontally between the jaws of Monsanto hardness tester one by one, and set the reading to zero, force the plunger until the tablet breaks and record the reading.

\subsubsection{Friability test.}

20 tablets of each brand were weighed using a digital analytical balance at 100 revolutions approx. $5 \mathrm{~min}$ in Roche friabilator, again the weight was recorded after weighing of de-dusted tablets as the tablet weight was lost due to abrasion and calculated by following formula [18]

$$
=\frac{\text { Minimum } / \text { Maximum weight }- \text { average weight } \times 100}{\text { Average weight }}
$$

\subsubsection{Thickness.}

Five tablets were taken, and their thickness was calculated by using Vernier calipers. It is expressed in mm. Uniformity of content: It is used to determine the drug content. 10 tablets were taken and crushed in powder form using mortar and pestle. Add 100mg of the powdered drug in a container by keeping volume $300 \mathrm{ml}$ with methanol and sonicated for $15 \mathrm{~min}$. Further, add $200 \mathrm{ml}$ of methanol and sonicate. Then give the third addition of methanol at room temperature and place aside the flask. Absorbance was determined by using HPLC for the drug content [24].

\subsubsection{Dissolution test for In-vitro bioequivalence study.}

In-vitro dissolution is a necessary element in the development of a drug as shown in equation 1, also used for the determination of bioequivalence, as shown in Figure 3 [22]. c denotes the concentration of drug where $t$ is then taken to dissolve the amount of drug in the body which start from initial zero (0).

$$
\text { Drug Release }(\%)=\frac{\text { Released drug }\left(\frac{\mathrm{mg}}{\mathrm{ml}}\right)}{\text { Label drug content }(\mathrm{mg})} X 100 \ldots \ldots \ldots \text { eqn1 }
$$

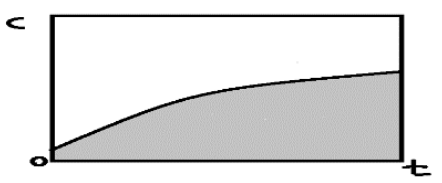

Figure 3. Pharmaceutical dosage form drug dissolution.

\subsubsection{Dissolution Condition for Gliclazide.}

a) Dissolution Medium: 900ml of Phosphate buffer $\mathrm{pH} 7.4$ (Weigh 6.8gm Potassium Dihydrogen Phosphate in $1000 \mathrm{ml}$ water and maintain $\mathrm{pH} 7.4$ with 2N Sodium Hydroxide). Apparatus: Paddle; RPM: 100 rpm; Time: 45min. 
b) Sample solution: Place 1 tablet in each of 6 vessels containing 900ml Phosphate buffer PH 7.4, previously equilibrated at $37^{\circ} \pm 0.5^{\circ} \mathrm{C}$, rotate the paddle at $100 \mathrm{rpm}$ for $45.0 \mathrm{~min}$. After completion of 45.0 min withdrawn $10 \mathrm{ml}$ sample and filter through $0.45 \mu$ nylon membrane filter. [17]

c) Chromatography:

It is a technique for mixture separation and used in the laboratory. The mixture is present in the mobile phase, which carries it through the stationary phase; various components present in the mixture will run at different velocity to reach the separation point. The principle of separation is based on differential partitioning. The different component will show their retention in the stationary phase [19].

High-performance liquid chromatography also called high-pressure liquid chromatography used in analytical chemistry to for separation, identifying, and quantifying mixture components. Archer John Porter Martin and Richard Laurence Millington Synge won the noble prize regarding the development of chromatographic techniques [20].

d) Chromatographic condition (HPLC):

Mobile Phase Preparation: A mixture of 0.1 volume of triethylamine, 0.1 volume of trifluoroacetic acid, 45 volumes of acetonitrile, and 55 volumes of water. Use filter and degas.

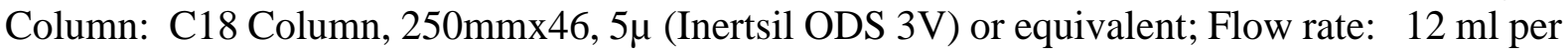

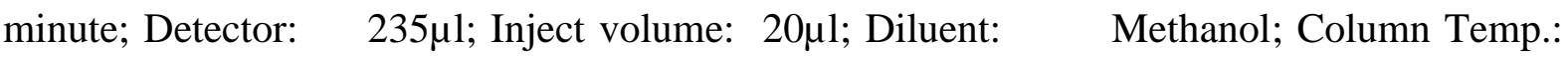
Ambient; Autosampler Temp: $15^{\circ} \mathrm{C}$

e) Preparation of standard solution: Weigh about $59 \mathrm{mg}$ of Gliclazide working standard $\&$ transfer into $100 \mathrm{ml}$ volumetric flask, add $20 \mathrm{ml}$ diluent, sonicate to dissolve, and makeup to volume with dissolution media. Dilute $3 \mathrm{ml}$ into $20 \mathrm{ml}$ volumetric flask and makeup to volume with dissolution media.

f) Procedure.

Inject the blank solution (As dissolution media) (in a single) into the liquid chromatography \& check for the proper baseline.

System Suitability: inject the standard solution in five replicate injections into the liquid chromatography and record the chromatograms. The tailing factor should not more than 2.0. The relative standard deviation for five replicate injection should be no more than $2.0 \%$. Inject the test solution (in a single for each) \& reference solution in single (bracketing) into the liquid chromatography \& record the chromatograms. The relative standard deviation of five replicate injection \& bracketing zones should be NMT 2.0\%. Measure the response for major peak areas of reference $\&$ test solution as shown in equation 2 mentioned below:

$$
=\frac{\mathrm{AT}}{\mathrm{AS}} X \frac{\mathrm{WS}}{100} X \frac{5}{20} X \frac{900}{1} X \frac{20}{4} X \frac{\mathrm{P}}{100} X \frac{100}{1000} \ldots \ldots \ldots \ldots \text { eqn } 2
$$

Where,

$\mathrm{AT}=$ Peak area obtained from test preparation.

$\mathrm{AS}=$ Average peak area.

$\mathrm{Ws}=$ working standard weight $(\mathrm{mg})$.

$\mathrm{P}=$ Potency of working standard in \%

$\mathrm{LC}=$ Label claim.

\subsubsection{Dissolution Condition for Metformin Hydrochloride.}

a) Dissolution medium: 900ml of Phosphate Buffer $\mathrm{pH} 6.8$ (Weight 6.8gm Potassium Dihydrogen Phosphate in $1000 \mathrm{ml}$ water and maintain $\mathrm{pH} 6.8$ with $2 \mathrm{~N}$ Sodium hydroxide. 
Apparatus: Basket 40\#; RPM: 100rpm; Time: 1, 3 \& 10 Hrs.

b) Sample Solution: Place 1 tablet in each of 6 vessels containing $900 \mathrm{ml}$ phosphate buffer $\mathrm{pH} 6.8$, previously equilibrated at $37^{\circ} \pm 0.5^{\circ} \mathrm{C}$, rotate the Basket $40 \#$ at $100 \mathrm{rpm}$ for 10.0 Hrs. After the different intervals, withdraw a $10 \mathrm{ml}$ sample, dilute $4 \mathrm{ml}$ this sample into $20 \mathrm{ml}$ volumetric flask, and makeup to volume with dissolution media. Filter through $0.45 \mu$ nylon membrane filter. Replace the dissolution media with $10 \mathrm{ml}$ of phosphate buffer (pH 6.8) after the withdrawal of the sample [17].

c) Chromatographic condition (HPLC):

Buffer preparation: Dissolve $935 \mathrm{mg}$ of 1- pentane sulfonic acid sodium salt monohydrate into 1-liter water and adjust pH 3.5 \pm 0.5 with Orthophosphoric acid.

Mobile Phase reparation: Prepare a suitable quantity a mixture of buffer ( $\mathrm{pH} 35)$, acetonitrile $(9: 1 \mathrm{v} / \mathrm{v})$, and mixed, filter, and degas.

Column: Hypersil BDS C18, 250mm x $4.6 \mathrm{~mm}, 5 \mu \mathrm{m}$ or equivalent; Flow rate: $1.0 \mathrm{ml}$ per minute Detector: 233nm; Injection: 10 $\mu$; Run time: 10min; Diluent: Acetonitrile: water (50:50); Column Temp.: $40^{\circ} \mathrm{C}$; Autosampler Temp: Ambient.

d) Preparation of standard solution: weight accurately about 44mg of Metformin HCL reference/working standard transfer in a $50 \mathrm{ml}$ volumetric flask, add about $30 \mathrm{ml}$ of diluent shake well to dissolve \& makeup the volume with diluent.

Dilute $5 \mathrm{ml}$ to $20 \mathrm{ml}$ with dissolution medium

e) Procedure: Inject the blank solution (As dissolution media) (in a single) into the liquid chromatography \& check for the proper baseline.

System Suitability: Inject standard solution in five replicate injection into the liquid chromatography and record the chromatograms. A Tailing factor should not more than 2.0. The relative standard deviation for five replicate injections should be not more than $2.0 \%$. Inject the test solution (in a single for each) \& reference solution in single (bracketing) into the liquid chromatography \& record the chromatograms. The relative standard deviation of five replicate injection \& bracketing zones should be NMT 2.0\%. Measure the response for major peak areas of reference $\&$ test solution, as shown in equation 3 mentioned below:

Calculation: Metformin Hydrochloride (in \%)

$$
=\frac{\mathrm{AT}}{\mathrm{AS}} X \frac{\mathrm{WS}}{100} X \frac{3}{20} X \frac{900}{1} X \frac{\mathrm{P}}{100} X \frac{100}{80} \ldots \ldots \ldots \ldots \ldots \text { eqn } 3
$$

\section{Results and Discussion}

The calculation of all the parameters is necessary because the slight variation in the evaluation parameters will show a drastic change in the in-vitro profile of drug formulations. On performing the experiment for the different parameters following are the observations as per Table 1. The average weight limit was set as per IP, and after calculation of the average weight of 20 tablets for each formulation, it was observed that the average weight of each formulation was found within the acceptance criteria $(1510.0 \mathrm{mg} \pm 5.0 \%)$ of reference formulation A. Uniformity of weight was calculated by using 20 tablets of each formulation A, $\mathrm{B}, \mathrm{C}, \mathrm{D}$ and the result of each B, C, D formulation was found within the limit (within $\pm 5.0 \%$ of average weight) as a comparison with reference formulation.

Hardness limit was NLT $6.0 \mathrm{Kg} / \mathrm{cm} 2$, and all the results after the experiment came within the acceptance criteria by using hardness tester and 10 tablets were taken for each formulation, including reference and test drugs. Friability test was performed for 20 tablets, 
and each formulation was shown the result within the limit (NMT 1.0\%w/w) for friability. After performing the experiment for evaluation parameters, it can be concluded that all the parameters are within the acceptance rage.

Table 1. Evaluation parameter of the tablets.

\begin{tabular}{l|l|l|l|l|l} 
Formulations & $\begin{array}{l}\text { Average weight } \\
\mathbf{( 1 5 1 0 . 0 m g} \pm \mathbf{5 . 0 \%}) \\
\mathbf{N = 2 0}\end{array}$ & $\begin{array}{l}\text { Uniformity of weight } \\
\text { (within } \pm \mathbf{5 . 0} \% \text { of } \\
\text { average weight) }\end{array}$ & $\begin{array}{l}\text { Hardness } \\
\text { (NLT } \\
\mathbf{6 . 0 K g} / \mathbf{c m}^{2} \text { ) }\end{array}$ & $\begin{array}{l}\text { Friability } \\
\text { (NMT } \\
\mathbf{1 . 0 \%} / \mathbf{w})\end{array}$ & $\begin{array}{l}\text { Thickness } \\
\mathbf{( 5 - 8 m m )}\end{array}$ \\
\hline Reference Formulation & $1526.36 \pm 31.24$ & $-0.76 \%$ to $+0.70 \%$ & $8.1 \pm 0.16$ & $0.50 \pm 0.010$ & $6.1 \pm 0.12$ \\
\hline Test Formulation A & $1518.44 \pm 31.16$ & $-0.78 \%$ to $+0.72 \%$ & $8.0 \pm 015$ & $0.25 \pm 0.005$ & $5.8 \pm 0.11$ \\
\hline Test Formulation B & $1523.80 \pm 31.35$ & $-0.77 \%$ to $+0.71 \%$ & $7.9 \pm 013$ & $0.36 \pm 0.007$ & $5.9 \pm 0.13$ \\
\hline Test Formulation C & $1529.50 \pm 31.31$ & $-0.79 \%$ to $+0.70 \%$ & $8.2 \pm 017$ & $0.44 \pm 0.008$ & $6.0 \pm 0.14$
\end{tabular}

\subsection{In-vitro evaluation test observations.}

As per the below-mentioned Figure 4, 5 it was found that the there was a slight variability in dissolution results of the generic copies of drugs as compared to the brand drug might be because of variation in batch to batch such as mixing method, granulation method, types of excipients and purity of API (active pharmaceutical ingredients).

Although the dissolution results of all the generic drugs are approx. near to the brand drug and within the limit, which means the rate of adsorption after administration will be similar, but it can't be ruled that the brand drug had the more standard curve as compared to the generic drug. The generic copies are less in cost as compared to brand drugs and approx. Similar in drug release patterns, so they are preferred.

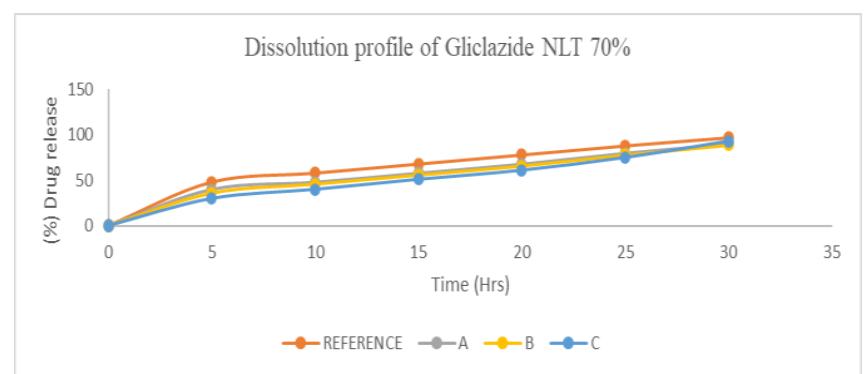

Figure 4. Dissolution profile of Gliclazide NLT $70 \%$.

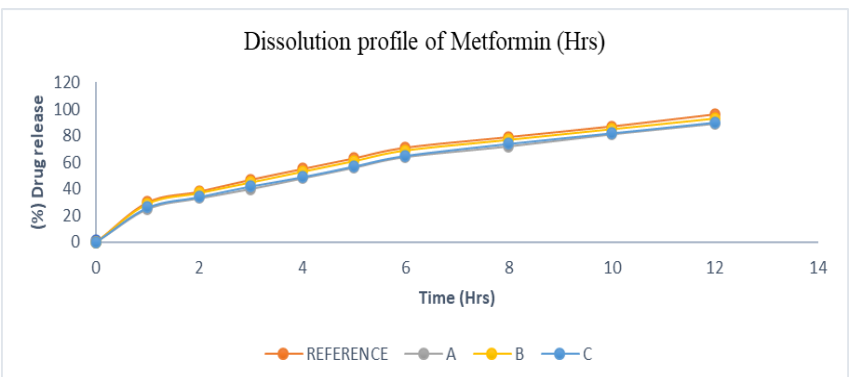

Figure 5. Dissolution profile of Metformin (Hrs).

Table 2. F1 and F2 values.

Similarity and Difference factor for Gliclazide

\begin{tabular}{l|l|l|l}
\hline Formula number & A & B & C \\
\hline F1 & 6 & 4 & 3 \\
\hline F2 & 58 & 70 & 71 \\
\hline
\end{tabular}

Similarity and difference factor for Metformin

\begin{tabular}{l|l|l|l}
\hline Formula number & A & B & C \\
\hline F1 & 5 & 6 & 9 \\
\hline F2 & 65 & 61 & 53
\end{tabular}




\subsubsection{Difference factor $F_{1}$.}

It is the difference in the dissolved percentage of the drug between the test and reference drug formulation at different time periods. This factor compares the difference in drug dissolved between test and reference solution and used to calculate the percentage drug release error [24].

The value of $\mathrm{f} 1$ should always be 0 to 15 , as observed in table D. F1 is given below in eq ${ }^{\mathrm{n}} 4$.

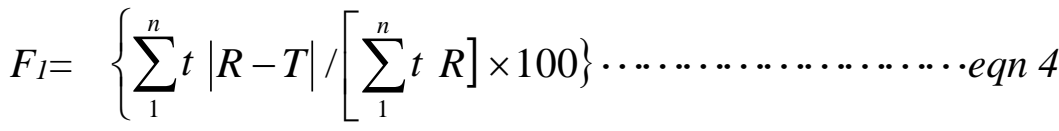

$$
\begin{aligned}
& R_{t}=\text { Dissolved Cumulative percentage of reference. } \\
& T_{t}=\text { Dissolved Cumulative percentage of the test. }
\end{aligned}
$$

\subsubsection{Similarity factor $F_{2}$.}

It is useful for the assessment of the nearness of the two formulations, F2 establish the comparison of the similarity of two dissolution profile. When the values of F2 come between 50 to 100 , then it denotes the similarity between two drug formulations, and this is the way to find out the dissolution similarity of two drugs. [24] If the manufacturing difference of drugs is major, then it can be found easily by calculating the similarity factor. F2 is given in equation 5 .

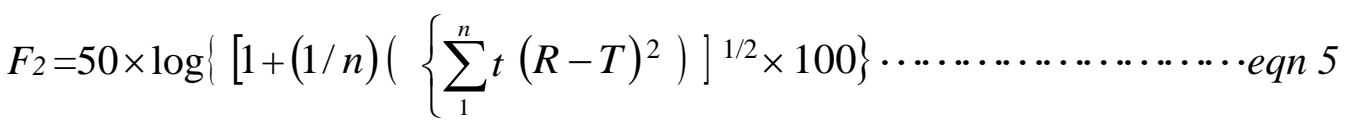

$$
\begin{aligned}
& \mathrm{Rt}=\text { Dissolved Cumulative percentage of reference. } \\
& \mathrm{Tt}=\text { Dissolved Cumulative percentage of the test. }
\end{aligned}
$$

After calculation of Similarity and difference factor as per above-mentioned table 2, it is observed that the calculated limit of F1(0 to 15) and F2 (50 to100)are within the specified limit of FDA which indicates the similarity in dissolution profile of generic and reference drug in terms of quality and adsorption of the drug. The combination of Gliclazide with metformin Hydrochloride sustained released tablet was taken. Numbers of brands are available in the market of this combination of the anti-diabetic drug. Always there is a confusion about whether the drug product has quality or not - the main objective of this study to find out the in-vitro bioequivalence of the drug combination. The in-vitro method was chosen as it is less costly as compared to the in-vivo method. The percentage release was determined by using Highperformance liquid chromatography. The drug (A, B, C) were subjected to evaluation tests that impact on in-vitro bioequivalence of a drug. Reference drug was taken as a brand drug and other A, B, C are generic drugs.

In the performed study, findings were established that the entire evaluation parameters and release results are complying with the limits as per Indian pharmacopeias.

\section{Conclusions}

In the performed experimental study generic drugs are compared with the brand drug through in-vitro bioequivalence study to know about the similarity in therapeutic activity between them, all the evaluation parameters such as hardness $\left(\mathrm{NLT} 6.0 \mathrm{Kg} / \mathrm{cm}^{2}\right.$ ), uniformity of 
weight (within $\pm 5.0 \%$ of average weight) and friability (NMT $1.0 \% \mathrm{w} / \mathrm{w}$ ), average weight $(1510.0 \mathrm{mg} \pm 5.0 \%)$ were found within the acceptable range. Similarity factor (F2) and dissimilarity factor (F1) were showing all most identical dissolution pattern for the anti-diabetic drugs it was found that the percentage drug release for the brand drugs $\mathrm{A}, \mathrm{B}, \mathrm{C}$ are approximately identical to reference drug hence all the formulations are contemplated as bioequivalent and useful in the treatment of diabetes.

The research specifies that the similarity between the brand and generic drugs is because of adequate supervision of the manufacturing and testing process is being done. However, the bioequivalence study is needed to check the therapeutic similarity between drugs from time to time.

\section{Funding}

This research received no external funding.

\section{Acknowledgments}

This research has no acknowledgment.

\section{Conflicts of Interest}

The authors declare no conflict of interest.

\section{References}

1. Birkett, D.J. Generics equal or not? Australian Prescriber 2003, 26, 85-7, https://doi.org/10.18773/austprescr.2003.063.

2. Ibarra, M.; Valiante, C.; Sopeña, P.; Schiavo, A.; Lorier, M.; Vázquez, M.; Fagiolino, P. Integration of in vitro biorelevant dissolution and in silico PBPK model of carvedilol to predict bioequivalence of oral drug products European Journal of Pharmaceutical Sciences 2018, 118, 176-182, https://doi.org/10.1016/j.ejps.2018.03.032.

3. Dowarah, J.; Singh, V.P. Anti-diabetic drugs recent approaches and advancements. Bioorganic \& Medicinal Chemistry 2020, 28, 1-195, https://doi.org/10.1016/j.bmc.2019.115263.

4. Cheng, C.L.; Yu, L.X.; Lee, H.L.; Yang, C.Y.; Lue, C.S.; Chou, C.H. Biowaiver extension potential to BCS Class III high solubility-low permeability drugs: bridging evidence for metformin immediate-release tablet. European Journal of Pharmaceutical Sciences 2004, 22, 297-304, https://doi.org/10.1016/j.ejps.2004.03.016.

5. Brem, H.; Tomic-Canic, M. Cellular and molecular basis of wound healing in diabetes. Journal of Clinical Investigation 2007, 117, 1219-1222, https://doi.org/10.1172/JCI32169.

6. Caspersen, C.J.; Thomas, G.D., Boseman, L.A.; Beckles, G. L. A.; Albright, A.L. Aging, Diabetes, and the Public Health System in the United States. American Journal of Public Health 2012, 102, 1482-1497, https://doi.org/10.2105/ajph.2011.300616.

7. Leslie, R.D. Predicting Adult-Onset Autoimmune Diabetes: Clarity from Complexity. Diabetes journal org. 2010, 59, 330-331, https://doi.org/10.2337/db09-1620.

8. Rother, K.I. Diabetes Treatment - Bridging the Divide. New England Journal of Medicine 2007, 356, 1499-1501, https://doi.org/10.1056/NEJMp078030.

9. Van Belle, T.L.; Coppieters, K.T.; Von Herrath, M.G. Type 1 Diabetes: Etiology, Immunology, and Therapeutic Strategies. Physiological Reviews 2011, 91, 79-118, https://doi.org/10.1152/physrev.00003.2010.

10. Todd, J.A. Etiology of Type 1 Diabetes. Immunity review Cell Press 2010, 32, 457-467, https://doi.org/10.1016/j.immuni.2010.04.001.

11. Bluestone, J.A.; Herold, K.; Eisenbarth, G. Genetics, pathogenesis and clinical interventions in type 1 diabetes. Nature Reviews 2010, 464, 1293-1300, https://doi.org/10.1038/nature08933.

12. Rathmann, W.; Giani, G. Global Prevalence of Diabetes: Estimates for the Year 2000 and Projections for 2030: Response to Wild. Diabetes Care 2004, 27, 2568-2569, https://doi.org//10.2337/diacare.27.10.2568.

13. Kim, C.; Newton, K.M.; Knopp, R.H. Gestational Diabetes and the Incidence of Type 2 Diabetes: A systematic review. Diabetes Care 2002, 25, 1862-1868, https://doi.org/10.2337/diacare.25.10.1862. 
14. Buchanan, T.A.; Xiang, A.H.; Page, K.A. Gestational diabetes mellitus: risks and management during and after pregnancy. Nature Reviews Endocrinology 2012, 8, 639-649, https://doi.org/10.1038/nrendo.2012.96.

15. Rena, G.; Hardie, D.G.; Pearson, E.R. The mechanisms of action of Metformin. Diabetologia Springer 2017, 60, 1577-1585, https://doi.org/10.1007/s00125-017-4342-z.

16. Gedawy, A.; Al-Salami, H.; Dass, C.R. Advanced and multifaceted stability profiling of the first-line antidiabetic drugs metformin, Gliclazide and glipizide under various controlled stress conditions. Saudi Pharmaceutical Journal 2020, 28, 362-368, https://doi.org/10.1016/j.jsps.2020.01.017.

17. Manley, L.; Hilden, J.; Valero, P.; Kramer, T. Tablet Compression Force as a Process Analytical Technology (PAT): 100\% Inspection and Control of Tablet Weight Uniformity. Journal of Pharmaceutical Sciences 2018, 1-9, https://doi.org/10.1016/j.xphs.2018.07.004.

18. Das, D.; Chakraborty, J.; Dash, S. Bioequivalence study of anti-diabetic activity between two marketed formulations of Metformin on glucocorticoid-induced hyperglycemia in rabbit. International Journal of Current Pharmaceutical Research 2017, 9, https://doi.org/10.22159/ijcpr.2017v9i4.20762.

19. Dembek, M.; Bocian, S. Pure water as a mobile phase in liquid chromatography techniques. TrAC Trends in Analytical Chemistry 2019, https://doi.org/10.1016/j.trac.2019.115793.

20. Patil, A.R.; Ghagare, P.M.; Deshmane, B.J.; Kondawar, M.S. Review on Chromatography Principal Types and its Application. Research journal of Pharmaceutical Dosage Forms and Technology 2020, 12, 27-32.

21. Maggi, L.; Canobbio, A.; Bruni, G.; Musitelli, G.; Conte, U. Improvement of the dissolution behavior of Gliclazide, a slightly soluble drug, using solid dispersions. Journal of Drug Delivery Science and Technology 2015, 26, 17-23, https://doi.org/10.1016/j.jddst.2015.01.002.

22. Costa, P.; Sousa Lobo, J.M. Modeling and comparison of dissolution profiles. European Journal of Pharmaceutical Sciences 2001, 13, 123-133, https://doi.org/10.1016/s0928-0987(01)00095-1.

23. Diagnosis and Classification of Diabetes Mellitus. Diabetes Care 2009, 3, S62-S69, https://doi.org/10.2337/dc10-s062.

24. Tajani, A.S.; Haghighizadeh A.; Soheili V.; Mirshahi S.; Rajabi O. In vitro bioequivalence study of 8 Brands of sertraline HCL tablet in Iran market. Biomedical and Pharmacology journal 2017, 10, 11091116, https://doi.org/10.13005/bpj/1210.

25. Santos Junior, A.F.; Barbosa, I.S.; Santos, V.L.; Silva, R.L.; Caetite Junior, E. Test of dissolution and comparison of in vitro dissolution profiles of coated ranitidine tablets marketed in Bahia, Brazil. Brazilian Journal of Pharmaceutical Sciences 2014, 50, 83-89, https://doi.org/10.1590/s1984-82502011000100008.

26. Xu, Z.S.; Zhu, H.Y.; Tang, C.R. Development and validation of a HPLC method for determination of sertraline in human plasma and its application to bioequivalence study. Latin American Journal of Pharmacy 2014, 33, 326-331

27. Shah V.P.; Tsong Y.; Sathe P.; Liu J. In vitro dissolution profile comparison-statistics and analysis of the similarity factor, f2. Pharmaceutical Research 1998, 15, 889-896, https://doi.org/10.1023/A:1011976615750.

28. Andrade, C.B.M.; Mylius, L.C.; Silva, N.M.; Steppe, M.; Schuck, V.J.A.; Shapoval, E.S.; Costa, T.D. Evaluation of the dissolution efficiency and similarity factor $\mathrm{f} 2$ for the comparison of dissolution profiles in-vitro. Revista Brasileira de Farmácia 2002, 83, 19-26, https://dx.doi.org/10.4314\%2Fahs.v13i2.25.

29. Hailu, G.S.; Gutema, G.B.; Hishe, H.Z.; Ali, Y.S.; Asfaw, A.A. Comparative In vitro Bioequivalence Evaluation of Different Brands of Amoxicillin Capsules Marketed in Tigray. Ethiopia International Journal of Pharmaceutical Sciences and Nanotechnology 2013, 6, 1966-1971. 